\title{
ANODISATION OF MEDICAL GRADE TITANIUM
}

Bálint Katona ${ }^{1}$, Lilla Nádai ${ }^{1}$, Attila Terdik ${ }^{1}$, Eszter Bognár ${ }^{1,2}$

${ }^{1}$ Budapest University of Technology and Economics, Faculty of Mechanical Engineering, Department of Materials Science and Engineering

${ }^{2}$ MTA-BME Research Group for Composite Science and Technology

katona@eik.bme.bu

\begin{abstract}
In recent years the number of titanium dental implants in use has significantly increased. At the same time bacterial infection of implants has become more common. The goal of our study was to develop a titanium-dioxide layer on the surface of titanium implant materials by anodisation with a view to impeding the attachment of contagious bacteria. In our experiments Grade 2 titanium and nanograin Grade 2 titanium discs were subjected to anodisation. We investigated the effect of voltage on the surface pattern of emerging titanium-dioxide. We examined the surfaces by reflected-light microscopy. We found that the value of the applied voltage and variation in grain size affected the thickness of the formed titanium-dioxide layer. These layers may promote or support desired forms of biological activity, such as cell attachment to integrate with bone.
\end{abstract}

Keywords: anodisation, titanium, Grade 2, nanograin, surface treatment

\section{Introduction}

Implant-associated infections have dramatically increased over the last decade in line with an unfortunate trend of growing resistance by bacteria to antibiotics. Bacterial infection can seriously compromise the success of an implant. ${ }^{1}$ One way to reduce bacterial colonisation of an implant might be to subject it to a surface treatment that gives the implant surface a texture which is difficult to colonise. Perhaps paradoxically, we are therefore trying to achieve a surface which impedes one kind of cellular attachment (bacterial) and yet promotes another kind of cellular attachment (osseointegrative, supporting attachment by bone cells).

Anodisation is an electrolytic surface treatment. The work piece is connected into a circuit as an anode immersed in an anodising bath. A cathode is immersed in the bath as well, made from the same or different material as the work piece. The most common geometries of the cathodes are sheet or roll. After closure of the circuit electrons can flow (Figure 1).
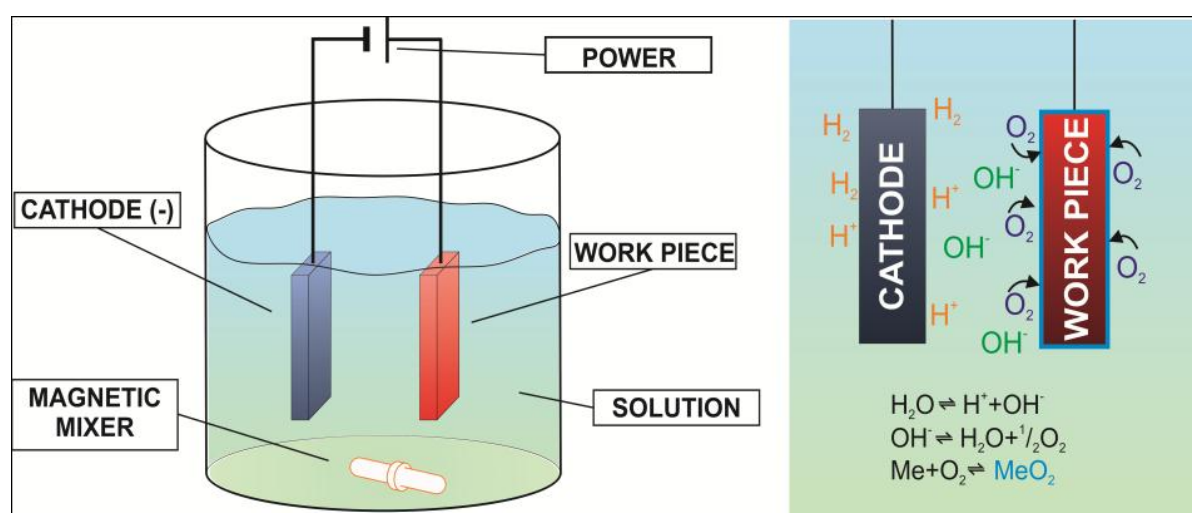

Figure 1. Schematic depiction of the anodisation experiment 
Because of the voltage, oxygen is released from the anodising bath, which reacts with the work piece. A metal-oxide layer is created on the surface, the thickness of which depends on the applied voltage and to some extent duration of immersion.

Aside from time, the process is jointly determined by the applied voltage, the composition of the anodising bath and the material comprising the work piece. With anodisation, metals can be coated whose oxides adhere to their surfaces. ${ }^{2-5}$

Chen and his colleagues in their work examined titanium-dioxide films of $0.3 \mathrm{~mm}$ thickness. Samples were mechanically polished and cleaned in acetone with ultrasonic cleaning equipment. Experiments were completed in a solution of $6 \mathrm{wt} \%$ hydrogen-fluoride. They used a cathode surface area of $9 \mathrm{~cm} 2$ at a distance of $1 \mathrm{~cm}$ from the anode, and at voltages of 40, 60, 80 and 100 $\mathrm{V}$, for durations of 2, 5 and 12 hours. They found that high hydrogen-fluoride concentration and voltage at $80 \mathrm{~V}$ are crucial for the formation of nanogrooves. ${ }^{6}$

Gong and his colleagues anodised pure titanium samples in $0.5 \mathrm{wt} \%$ hydrogen-fluoride mixture at $18^{\circ} \mathrm{C}$ for 20 minutes. They used magnetic mixing. It was found that nanotubular structures did not form if the applied voltage was more than $40 \mathrm{~V}$. They found that under an applied voltage of $20 \mathrm{~V}$ nanotubes were formed which had average diameter $60 \mathrm{~nm}$ and length $250 \mathrm{~nm}$.

The colour of the formed oxide layer depends on its thickness. For titanium this ranges across a wide spectrum allowing us to infer the thickness of the formed titanium-dioxide layer from its colour. 8

Puckett and his colleagues anodised films of pure (99.2\%) titanium. Before their experiments, the samples were chemically etched in a solution of hydrogen-fluoride and nitric acid to remove any surface contamination and the thin oxide layer. After this treatment the films were anodised in solution of $1.5 \mathrm{~V} / \mathrm{V} \%$ hydrogen-fluoride for 10 minutes at $20 \mathrm{~V}$. They found that nanotubularlike titanium-dioxide structures were created on the surface. In another experiment they performed the anodization in a solution of $0.5 \mathrm{~V} / \mathrm{V} \%$ hydrogen-fluoride at $20 \mathrm{~V}$ for 1 minute. They found the surface had acquired nanotexture.

Poznyak and colleagues anodised pure titanium samples with a titanium cathode. Before the experiment mechanical and chemical polishing were done in a warm hydrogen-fluoride and nitric acid solution. During anodisation, maximum current density was $10 \mathrm{~mA} / \mathrm{cm} 2$, and maximum voltage was higher than $1000 \mathrm{~V}$. The anodising bath they used was a mixture of nitric acid and distilled water. The depth of the created oxide layer was determined with Auger-spectroscopy, the phase composition was determined with X-ray diffraction, and the morphology of the surface was determined with scanning electron microscopy. They found that the density of the oxide layer was 3.2-3.9 g/ cm3, which was $180 \mathrm{~nm}$ thick, containing 4 to $5 \%$ sulphur from the acid. The thicker oxide layer was rougher, and where $\mathrm{d}<50 \mathrm{~nm}$ then it was amorphous, whereas if $\mathrm{d} \approx 100$ $\mathrm{nm}$ then it was composed of atanase. If $\mathrm{d} \approx 300 \mathrm{~nm}$ then the oxide layer contained both atanase and rutile ${ }^{10}$

In his research, Elias treated with a range of processes discs and dental implants made of one type of pure titanium. The etching pickle was a solution of nitric acid, hydrochloric acid and sulphuric acid. He found that chemically etched homogeneously rough surfaces were more biologically active in the osseointegrative sense. This facilitated the attachment of bone cells so the implants would support mechanical loading. The electrolytic solution for anodisation 
contained calcium and phosphorus and he used micro-arc oxidation based on previous research. ${ }^{11}$ He found that various treatments differently changed surface morphology and therefore the anodised samples needed greater torque to screw into bone than chemically etched implants. ${ }^{12}$

Gubicza and his colleagues in their research manufactured ultrafine-grained titanium with equal channel angular pressing, which known as ECAP technology and the combination of modern and conventional plastic deformation techniques. The formed grain size was 200-500 nm using ECAP and 50-300 nm using a combination of the ECAP, forging and drawing. They found that this material had increased yield stress $(652 \mathrm{MPa})$ and increased dislocation density $(24 \times 1014 \mathrm{~m}$ 2). ${ }^{13-14}$

\section{Methods and materials}

In our experiments we used $13 \mathrm{~mm}$-diameter titanium rods out of which we machined $2 \mathrm{~mm}$ thick discs. We used two types of base material: pure titanium, known as Grade 2, and nanograin Grade 2 pure titanium. The latter is prepared using ECAP. The two materials vary only in grain size.

After making these discs we cut each disc into 4 identical quarters with a diamond disc cutter. The machining left burr and surface imperfections so we applied chemical etching to remove these. During treatment we used ultrasonic cleaning equipment. We used a mixture of $12 \mathrm{~V} / \mathrm{V} \%$ nitric acid, $9 \mathrm{~V} / \mathrm{V} \%$ hydrogen-fluoride, and distilled water. Based on our preliminary experiments the time of the chemical etching was chosen as 30 seconds. We kept the temperature at $30 \pm 1^{\circ} \mathrm{C}$. The chemical etching successfully removed the burr and surface imperfections caused by machining and cutting. ${ }^{15}$

To further smooth surfaces we electropolished the chemically etched samples. We kept the temperature at $30 \pm 1^{\circ} \mathrm{C}$ during the process. We used $20 \mathrm{~V}$ and a 3 -minute duration. After this we applied anodisation on the resulting work pieces.

We held samples with a clip of nickel-coated 316L austenitic stainless steel. This material transferred power to the sample. The clip did not touch the anodising bath. The cathode was a cylindrical mesh of $316 \mathrm{~L}$ austenitic stainless steel.

Because the main criteria for the anodising bath were its oxygen and acidic properties we used a mixture of $0.1 \mathrm{~V} / \mathrm{V} \%$ hydrogen-fluoride and distilled water. We chose this concentration based on preliminary tests.

The applied voltages were between 10 and $200 \mathrm{~V}$. The necessary voltages we created with a toroidal transformer. The exact value of the voltage in the circuit depends on the conductivity of the anodising solution and on the current limit. Over-high current density can cause problems so we limited this with a current limit, which stopped the voltage rising further during anodising. Exact values of the applied voltages of the samples are given in Table 1.

\begin{tabular}{|l|l|l|l|l|l|l|l|l|l|l|l|l|l|l|l|l|l|l|l|l|}
\hline Nr. & 1 & 2 & 3 & 4 & 5 & 6 & 7 & 8 & 9 & 10 & 11 & 12 & 13 & 14 & 15 & 16 & 17 & 18 & 19 & 20 \\
\hline $\mathbf{U}[\mathbf{V}]$ & 10 & 20 & 30 & 40 & 50 & 60 & 70 & 80 & 90 & 100 & 110 & 120 & 130 & 140 & 150 & 160 & 170 & 180 & 190 & 200 \\
\hline
\end{tabular}

Table 1. The values of the anodising voltage of the samples 
In preliminary anodising experiments we treated samples for durations of 1, 5 and 10 minutes and observed the formed oxide layer. We found this layer formed immediately so in the actual experiments we stopped when applied voltage reached the required value. During the process we used magnetic mixing with $150 \mathrm{rpm}$ to keep the anodising solution in motion. The temperature of the anodising bath was $20 \pm 1{ }^{\circ} \mathrm{C}$.

\section{Results and discussion}

We examined the formed surfaces with reflected-light microscopy. On images we can see that different voltage resulted in differently coloured titanium-dioxide layers (Figures 2-3). The colour is closely related to the thickness of the layer. Figures 4-5 shows the reflected-light microscopy images of the anodised surfaces.

The two different types of base materials have the same chemical composition, they vary only in grain size. The grain size influences mechanical properties (e.g. tensile strength, hardness, dislocation density) as well as electrical properties (e.g. conductivity). On images we found that different grain sizes resulted in different oxide layer thicknesses at the same voltage value. We can conclude this from oxide colours, which closely track thickness.

On images we found local surface heterogeneities in titanium-dioxide layers. These are due to material defects, work piece shape, and uneven voltage distribution. The size of these heterogeneous areas stayed low at low applied voltages (10-100 V) but rise at higher voltages (100-200 V). This phenomenon held for both materials.
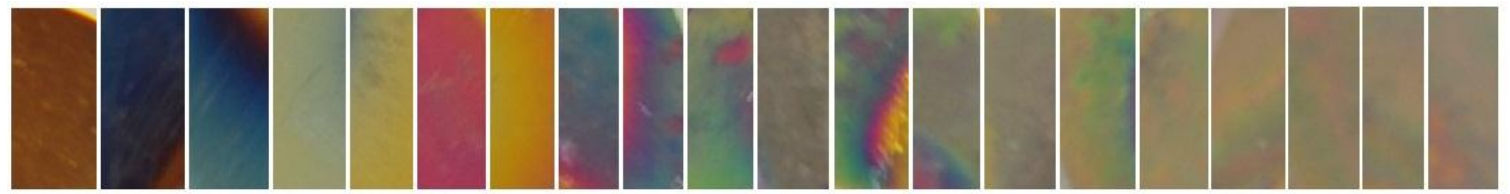

Figure 2. Sections of surfaces of the anodising Grade 2 titanium discs, with voltage changing from left to right from 10 to $200 \mathrm{~V}$ in $10 \mathrm{~V}$ increments

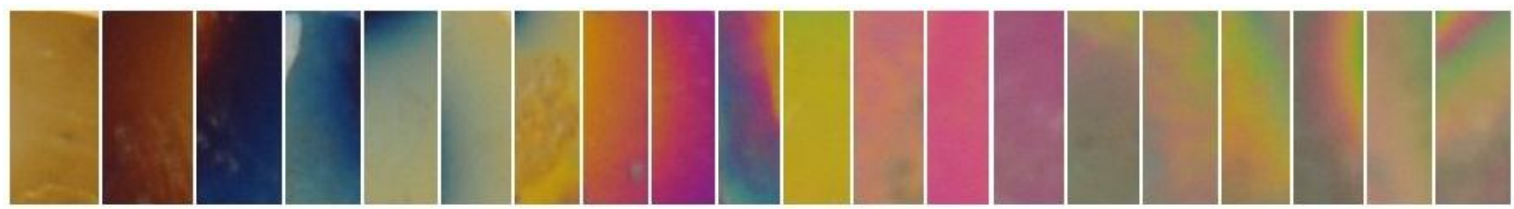

Figure 3. Sections of surfaces of the anodising nanograin Grade 2 titanium discs, with voltage changing from left to right from 10 to $200 \mathrm{~V}$ in $10 \mathrm{~V}$ increments

To observe possible nanostructures formed on the surface we have to use atomic-force microscopy. This gives higher-resolution images of the surface.

To observe the biological behaviour of these surfaces, bacteriological experiments were needed. Based on these we concluded that the formed titanium-dioxide layer can support osseointegration. 

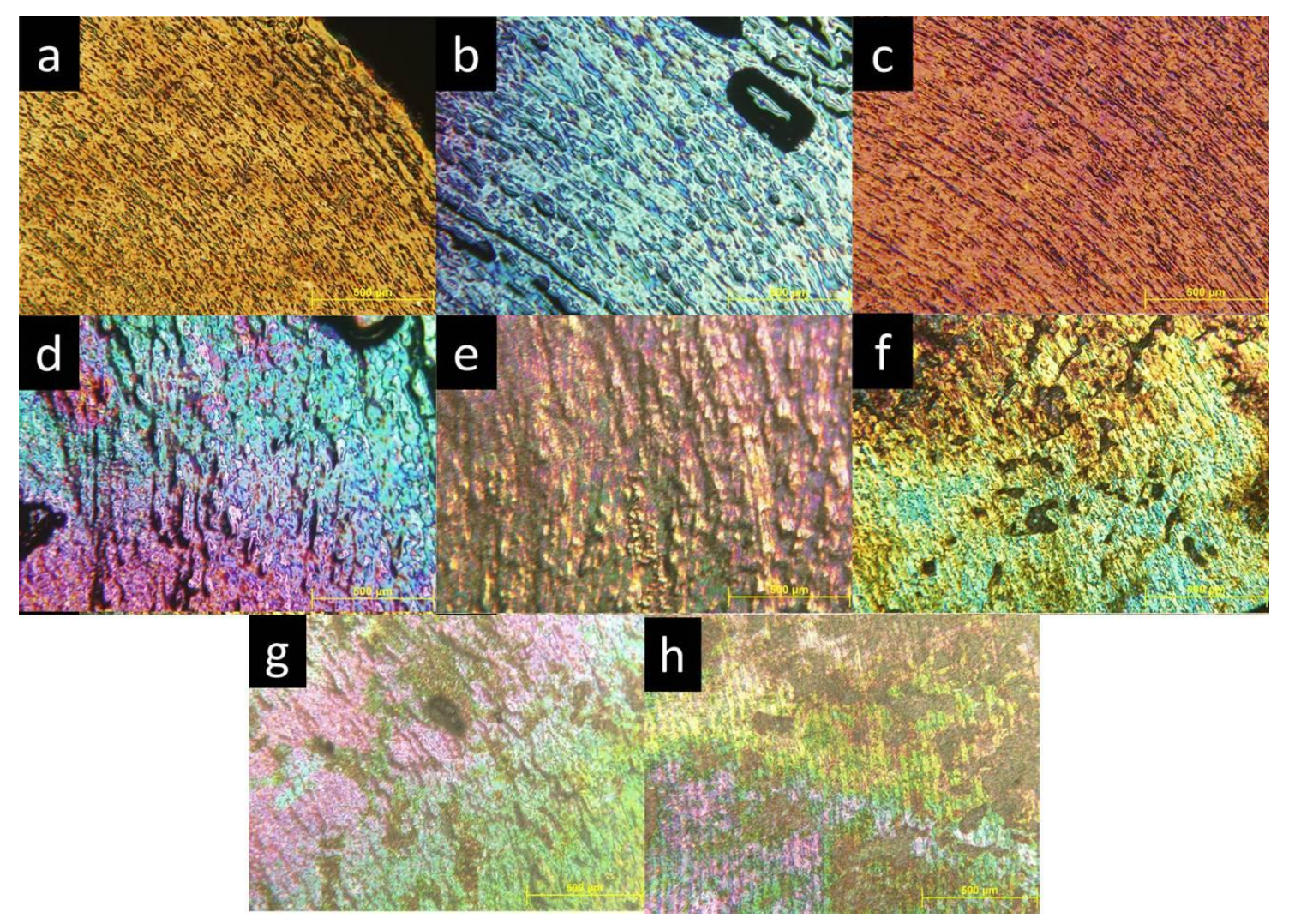

Figure 4. Reflected-light microscopy pictures of surfaces of the anodised Grade 2 titanium discs, $10 \mathrm{~V}$ (a), $30 \mathrm{~V}$ (b), $60 \mathrm{~V}$ (c), $90 \mathrm{~V}$ (d), $120 \mathrm{~V}$ (e), $150 \mathrm{~V}$ (f), $180 \mathrm{~V}$ (g), $200 \mathrm{~V}$ (h)

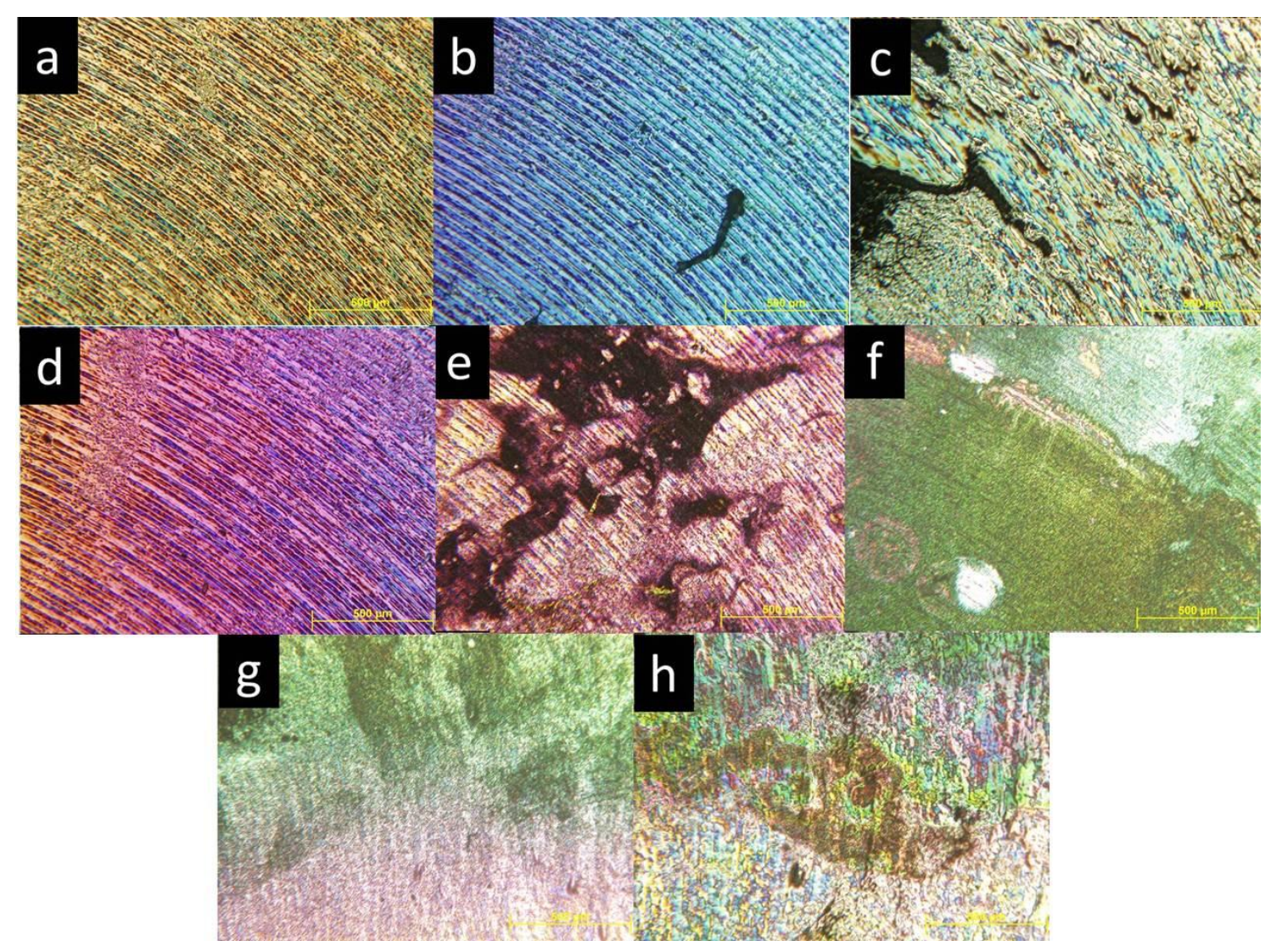

Figure 5. Reflected-light microscopy pictures of surfaces of the anodised nanograin Grade 2 titanium discs $10 \mathrm{~V}$ (a), $30 \mathrm{~V}$ (b), $60 \mathrm{~V}$ (c), $90 \mathrm{~V}$ (d), $120 \mathrm{~V}$ (e), $150 \mathrm{~V}$ (f), $180 \mathrm{~V}$ (g), $200 \mathrm{~V}$ (h) 


\section{Conclusion}

In our study we worked on disc segments of pure titanium, known as Grade 2 titanium, and nanograin Grade 2 pure titanium. Both materials can be used for medical implants. Before anodisation we treated the specimens with chemical etching and electropolishing. Chemical etching removed burrs and surface contamination, while electropolishing smoothed the surface.

For the anodising experiments applied voltages were between 10 and $200 \mathrm{~V}$. The anodising bath was a mixture of $0.1 \mathrm{~V} / \mathrm{V} \%$ hydrogen-fluoride and distilled water and the temperature was $20{ }^{\circ} \mathrm{C}$. During the process we used magnetic mixing.

Reflected-light microscopy images show that different voltages resulted in differently coloured titanium-dioxide layers, indicating varying thicknesses. On images we found that different grain sizes resulted in different oxide-layer thicknesses at the same voltage value. We found these layers contained local heterogeneities whose size increased with voltage.

Based on our experiments we can conclude that it is possible to create titanium-dioxide layers on the surface of pure titanium, and nanograin pure titanium. The thickness of the formed oxide layer depends mainly on the applied voltages and on the grain size.

\section{REFERENCES}

1. Tanner A, Maiden MFJ, Lee K, Shulman LB, Weber HP. Dental Implant Infections. Clinical Infectious Diseases, 1997; 25(2):213-217, DOI: 10.1086/516243.

2. Yu X, Li Y, Wlodarski W, Kandasamy S, Kalantar-Zadeh K. Fabrication of nanostructured TiO2 by anodization: A comparison between electrolytes and substrates. Sensors and Actuators, 2008;130(1):2531, DOI:10.1016/j.snb.2007.07.076.

3. Macak JM, Tsuchiya H, Schmuki P. High-Aspect-Ratio TiO2 Nanotubes by Anodization of Titanium. Angewandte Chemie Internaitonal Edition, 2005;44(14)2100-2, DOI: 10.1002/anie.200462459.

4. Paulose M, Prakasam HE, Varghese OK, Peng L, Popat KC, Mor GK, Desai TA, Grimes CA. TiO2 Nanotube Arrays of $1000 \mu \mathrm{m}$ Length by Anodization of Titanium Foil: Phenol Red Diffusion. The Journal of Physical Chemistry C, 2007;111(41):14992-7, DOI: 10.1021/jp075258r.

5. Mor GK, Varghes OK, Paulose M, Grimes CA. Transparent Highly Ordered TiO2 Nanotube Arrays via Anodization of Titanium Thin Films. Advanced Functional Materials, 2005;15(8):1291-6, DOI:10.1002/adfm.200500096

6. Chen Y, Wang XM, Lu SS, Zhang X. Formation of titanium oxide nanogrooves island arrays by anodization. Electrochemistry Communications, 2010;12(1):86-9.

7. Gong D, Grimes CA, Varghese OK, Wenchong HU, Singh RS, Chen Z, Dickey EC. Titanium oxide nanotube arrays prepared by anodic oxidation. Journal of Materials Research, 2001;16(12):3331-4, DOI: $10.1557 / J M R .2001 .0457$.

8. Diebold U. The surface science of titanium dioxide. Surface Science Reports, 2003;48(5-8):53-229, DOI: 10.1016/S0167-5729(02)00100-0.

9. Puckett SD, Taylor E, Raimondo T, Webster TJ. The relationship between the nanostructure of titanium surfaces and bacterial attachment, Biomaterials, 2010;31:706-713, DOI: 10.1016/j.biomaterials.2009.09.081.

10. Poznyak SK, Talapin DV, Kulak AI. Electrochemical oxidation of titanium by pulsed discharge in electrolyte. Journal of Electroanalytical Chemistry, 2005;579:299-310. 
11. Li LH, Kong YM, Kim KW, Kim YW, Kim HE, Heo SJ, Koak JY. Improved biological performance of Ti implants due to surface modification by micro-arc oxidation. Biomaterials, 2004;25:2867-75.

12. Elias CN. Titanium dental implant surfaces. Revista Matéria, 2010;15:138-42.

13. Gubicza J, Fogarassy Zs, Krállics Gy, Lábár J, Törköly T. Microstructure and mechanical behavior of ultrafine-grained titanium. Materials Science Forum, 2008;589:99-104.

14. Krállics Gy, Malgin D, Raab GI, Alexandrov IV. Ultrafine Grained Materials III (eds). Proceedings of 2004 TMS Annual Meeting, Charlotte, North Carolina.

15. Nádai L, Katona B, Terdik A, Nagy P, Weszl M, Bognár E. Chemical etching and electropolishing of titanium. XVIII. FMTÜ, 2013:265-68, ISSN 2067-6 808.

We would like to thank Liza Pelyhe, Torda Sélley, and Dávid Pammer for their contributions and for their help with the measurements. Special thanks for Miklós Weszl for his help and György Krállics for supplying the nanograin titanium rods.This work is connected to the scientific program of the "Development of quality-oriented and harmonized $R+D+I$ strategy and functional model at BME" project. This project is supported by the New Hungary Development Plan (Project ID: TÁMOP-4.2.1/B09/1/KMR-2010-0002). 